\title{
Imported Falciparum Malaria in British Troops Returning from Kenya
}

\author{
Capt J H Miller \\ MB, MRCP(UK), Dip IMC RCS (Ed), RAMC \\ Senior House Officer
}

Maj M Byers

MB, MRCGP, DA, DRCOG, Dip IMC RCS (Ed), RAMC*

General Practice Vocational Trainee

\author{
Lt Col R Whiteoak \\ $M B, M A, M R C P(U K)$, RAMC \\ Consultant Physician \\ Duchess of Kent's Military Hospital, Catterick Garrison, North Yorks DL9 4DF
}

\author{
D A Warrell \\ Consultant Advisor in Malariology to the British Army \\ Professor of Tropical Medicine, University of Oxford
}

SUMMARY: The objective of this study was to report on a breakthrough of Plasmodium falciparum infection $\stackrel{\dot{\omega}}{\omega}$ following a military exercise in central Kenya and the treatment regimens used. A series of case reports are $\bigcirc$ presented from the three UK hospitals involved.

Among 150 British soldiers who had been on exercises for five weeks in central Kenya, taking proguanil/chloroquine anti-malarial prophylaxis, seven developed symptomatic falciparum malaria. Initian symptoms, which started between 2 and 10 days before their return to England, included faintness, sweating shivering, diarrhoea, headache and myalgia. Diagnosis was delayed from between 5 and 13 days after the first symptom. One patient was severely ill with $\mathbf{5 0 \%}$ parasitaemia: he required intensive care, exchange blood transfusion and haemofiltration for acute renal failure. Compliance with chemoprophylaxis was not measured and anti-mosquito measures were not generally practised. However, British Army policy was amended in June 1993 son that mefloquine will be used in future rather than proguanil/chloroquine.

It was concluded therefore that even in an educated and motivated population simple preventive measures are not observed. Chemoprophylactic compliance could be improved by changing to a simpler regime. Falciparum malaria is a medical emergency that requires urgent admission for confirmation of diagnosis, supportive and curative treatment. Its presence should be suspected in any ill traveller.

\section{Introduction}

The incidence of malaria due to Plasmodium falciparum is increasing in the UK (1). Twelve deaths occurred out of 2332 notified cases in 1991 and 11 out of 1629 in 1992 (2). These deaths were associated with a delay in diagnosis rather than delay in presentation (3). So clinical suspicion of malaria must remain high in any unwell traveller who has returned from an endemic area.

\section{Case Reports}

We describe seven patients. Five were treated at the Duchess of Kent's Military Hospital (DKMH), Catterick, one at a local district general hospital and one at the John Radcliffe Hospital, Oxford. All were male soldiers who had returned from a five week company strength (150 men) exercise at Mpala Farm, near Nanyuki, central
Kenya. Cases 1-6 had also participated in a sub-group exercise ( 21 men) during which they had travelled through the bush at night, slept in the open air by day and not taken any precautions against mosquito bites. At the end of the exercise the sub-group went on a camel safari through the bush in the same area. All the soldiers had received a pre-tour lecture on illness prevention measures in the tropics. They were instructed/ordered to take chloroquine sulphate $300 \mathrm{mg}$ (base) weekly and proguanil $200 \mathrm{mg}$ daily starting one week before departure and continuing for four weeks after return. Mosquito nets and $\frac{D}{O}$ diethyl toluamide (DEET) liquid repellant were available in Kenya. The Regimental Medical Officer (RMO), who $N$ is a principal in general practice, recommended and $N$ oversaw these preparations (Table 1).

\footnotetext{
*Now a principal in general practice in the North of England
} 
Table 1 - Preventive Measures

(Information from direct interviews by one author)

\begin{tabular}{lllll}
\hline & $\begin{array}{l}\text { Chemoprophylaxis } \\
\text { Compliance (1) }\end{array}$ & $\begin{array}{l}\text { Appropriate } \\
\text { Clothing (2) }\end{array}$ & $\begin{array}{l}\text { Use of } \\
\text { Mosquito } \\
\text { Nets (3) }\end{array}$ & $\begin{array}{l}\text { Insect } \\
\text { Repellant } \\
\text { Use (4) }\end{array}$ \\
Case 1 & + & & & - \\
Case 2 & + & - & - & - \\
Case 3 & + & + & - & - \\
Case 4 & - & - & - & - \\
Case 5 & - & + & - & - \\
Case 6 & - & - & - & + \\
Case 7 & + & + & + & + \\
\hline
\end{tabular}

1. Perfect compliance $(+)$ or admitted dubious compliance $(-)$.

2. Use of long sleeves and trousers at dusk $(+)$ or not $(-)$.

3. Use every night $(+)$ or not $(-)$.

4. Personal daily use of diethyl toluamide (as issued) in the bush (+) or not (-).

Case 1 took his anti-malarial chemoprophylactic drugs as instructed but did not take any precautions against mosquito bites. As a result he was bitten frequently. He spent most of the time around Mpala Farm but at the end of the tour joined the camel safari. He was well until 15 April when, while still in Kenya, he felt faint and shivery while shopping. He consulted the medical officer who prescribed paracetamol but did not suggest any investigations. The patient went to bed but was soon forced to resume some duties. He developed mild diarrhoea. He was due to fly back to UK on 19 April and by that time felt extremely ill and was scarcely able to get on to the plane unaided. When he landed at RAF Brize Norton he was driven by ambulance to the Churchill Hospital, Oxford where he was admitted to the infectious diseases ward at about midnight. The first blood slide showed a $25 \%$ P. falciparum parasitaemia (mature trophozoites) and he was started on quinine (loading dose). He was then transferred to the intensive care unit at the John Radcliffe Hospital. He was complaining of breathlessness and pain on taking a deep breath. His legs were extremely tender and could not bear his weight. He had noticed jaundice for about 24 hours. In passing he mentioned that another soldier in his group, Case 2, had also developed jaundice and intermittent fever during the last week they were in Kenya.

On examination he was fully conscious with marked jaundice but no haemorrhages. Pulse 120 per minute regular, blood pressure $120 / 75$, auscultation normal. He was markedly tachypnoeic. The abdomen was rigid and very difficult to palpate but ultrasound confirmed hepatosplenomegaly (spleen $14 \mathrm{~cm}$ ). The muscles of his thighs, calves and nuchal region were very tender to palpation. He had already had one episode of hypoglycaemia $(1.9 \mathrm{mmol} / \mathrm{l})$ since starting quinine treatment.
Investigations revealed marked thrombocytopenia ( $20 \mathrm{x}$ $10^{9} / 1$, sodium $127 \mathrm{mmol} / 1$, potassium $4.7 \mathrm{mmol} / 1$, urea $40.7 \mathrm{mmol} / \mathrm{l}$ creatinine $595 \mathrm{mmol} / \mathrm{l}$, albumin $32 \mathrm{~g} / \mathrm{l}$, total bilirubin $140 \mathrm{mmol} / \mathrm{l}$, creatine kinase $396 \mathrm{iU} / \mathrm{l}$, aspartate aminotransferase $279 \mathrm{iU} / 1$, alkaline phosphatase 30 हू iU/1. The blood lactate was extremely high at 20 . mmo1/1, C-reactive protein $297 \mathrm{mg} / 1$.

Treatment in the Intensive Care Unit from 20-27 Aprif included haemofiltration, two exchange bloo $\$$ transfusions of 4 units each because of his persistent hyperparasitaemia, which had reached a peak of $50 \%$ o 20 April, and platelet transfusions. He developed shadowing on the chest radiograph consistent with hypostatic pneumonia and possibly ARDS and became hypoxaemic. He was given oxygen by mask but was not mechanically ventilated. His parasitaemia fell to $16 \%$ on 21 April and disappeared over the next few days. On 27 April he was transferred to the Renal Unit where he had further haemofiltration and diuretic treatment and was transferred on 4th May to a renal unit in Yorkshire. He was allowed home after 7 days.

Case 1 was the index case. Others with similar exposure were at risk and with this in mind the medical centre at RAF Brize Norton was alerted by the John Radcliffe Hospital team to the potential risk to the rest of the party on 20 April 1993.

Case 2 was referred to DKMH by the RMO immediately on return to UK on 20 April 1993. He had felt unwell for four days before flying home. In Kenya he was initially assessed by a regimental para-medic and discharged after a day's rest when his symptoms of sweats and myalgia had subsided. Jaundice was not noted. He had not used a mosquito net or repellant although he had been sleeping outdoors beside a swamp while on 
exercises. He claimed to have taken chemoprophylaxis as tablet parades were held within his sub-unit. The clinical and laboratory features are listed in Tables 2 and 3.

Table 2

Clinical Features on Admission

\begin{tabular}{|c|c|c|c|c|c|c|c|c|}
\hline Case No & Age & Sex & $\begin{array}{l}\text { Delay to } \\
\text { Presentation }\end{array}$ & $\begin{array}{l}\text { Delay to } \\
\text { Diagnosis }\end{array}$ & Fever & $\begin{array}{l}\text { Flu } \\
\text { Symptoms }\end{array}$ & Hepatomegaly & $\begin{array}{l}\text { Palpable } \\
\text { splenomegaly }\end{array}$ \\
\hline & & & (1) & (2) & (3) & & & \\
\hline 1 & 27 & M & 1 & 5 & 36.5 & Yes & $6 \mathrm{~cm}$ & $14 \mathrm{~cm}$ \\
\hline 2 & 26 & M & 1 & 7 & 37.5 & Yes & $2 \mathrm{~cm}$ & Tip \\
\hline 3 & 24 & $\mathrm{M}$ & 4 & 10 & 39.0 & Yes & Yes & No \\
\hline 4 & 36 & M & 5 & 5 & None & Yes & No & No \\
\hline 5 & 18 & M & 5 & 5 & 39.0 & Yes & No & No \\
\hline 6 & 21 & M & 7 & 7 & 40.0 & Yes & No & No \\
\hline 7 & 35 & M & 3 & 13 & 39.5 & Yes & No & No \\
\hline
\end{tabular}

1. Delay in days from onset of symptoms to presenting to the medical support chain.

2. Delay in days from onset of symptoms to diagnosis.

3. Oral temperatures ${ }^{\circ} \mathrm{C}$.

Table 3 - Laboratory Findings on Admission and Eventual Treatment

\begin{tabular}{lllllll}
\hline $\begin{array}{l}\text { Case } \\
\text { No }\end{array}$ & $\begin{array}{l}\text { \% Paras- } \\
\text { itaemia }\end{array}$ & $\begin{array}{l}\text { White Cells } \\
\mathbf{x} \mathbf{1 0} / \mathbf{1}\end{array}$ & $\begin{array}{l}\text { Platelets } \\
\mathbf{x} \mathbf{1 0} / \mathbf{1}\end{array}$ & $\begin{array}{l}\mathbf{H b} \\
\text { g/dl }\end{array}$ & $\begin{array}{l}\text { Malaria } \\
\text { IFAT* }\end{array}$ & $\begin{array}{l}\text { Treatment } \\
\text { ** }\end{array}$ \\
\hline 1 & 50 & 4.6 & 20 & 12.0 & - & $\begin{array}{l}\text { IV + oral Q } \\
+ \text { Dox }\end{array}$ \\
2 & 1 & 8.0 & 57 & 14.5 & - & Oral Q + T \\
3 & 3 & 7.0 & 120 & 13.9 & pos & $\begin{array}{l}\text { IV + oral Q } \\
\text { Oral Mef }\end{array}$ \\
4 & 0.1 & 5.2 & 94 & 13.6 & - & Oral Q + T \\
5 & 2 & 4.3 & 20 & 15.6 & pos & Oral Q + T \\
6 & 0 & 4.2 & 121 & 13.0 & pos & Oral Q + T \\
7 & 2 & 5.2 & 92 & 14.3 & pral Q + T \\
\hline
\end{tabular}

* Immofluorescence Antibody against Plasmodium falciparum

** Treatment regimes: Q - Quinine 600mg tds seven days

$\mathrm{T}$ - Tetracycline $250 \mathrm{mg}$ qds seven days

Mef - Mefloquine 500mg bd one day

Dox - Doxycycline 100mg od seven days

Case 3 was admitted to North Tees General Hospital on 20th April 1993 by the family GP when the patient arrived at his parents' home feeling unwell. He had been ill for the past ten days with malaise and sweats. He had consulted a regimental para-medic while on exercises but no specific action was taken. In hospital he was treated with a week's course of oral quinine $600 \mathrm{mg}$ tds and discharged after three days with the remaining doses to be taken at home. On 13 May 1993 he was re-admitted with a recrudescence of falciparum malaria and was treated with intravenous and then oral quinine followed by mefloquine. On 14th June he was again admitted feeling unwell with a low grade fever but no parasites were detected on blood film examination. He was discharged feeling better after three days with no further treatment. Routine follow-up was arranged at DKMH.

Since Cases 1, 2 and 3 all had a similar exposure history the rest of the group was felt to be at risk. On 20th April the regimental headquarters was requested to recall all twenty one men who had been on the camel safari. They reported to DKMH over the period from 21 to 26 April.

Case 4 had suffered from diarrhoea two days before leaving Kenya. He saw the RMO three days after returning to the UK on 22nd April with persistent bowel upset and myalgia. He was admitted to DKMH. After starting oral quinine and tetracycline for a $0.1 \%$ falciparum parasitaemia he developed fever and a severe 
headache with photophobia and mild neck stiffness. This settled on hydration, simple analgesics and continuation of oral treatment. He admitted to having missed some doses of his chemoprophylaxis

Case 5 felt unwell in Kenya. He attended DKMH on 21 st April when called back from leave. Two months earlier he had been in Oman for several weeks where he was well. He admitted to wearing sports kit (shorts and vest) at dusk while in Kenya. He stopped his chemoprophylaxis on his return to UK because he had run out of drugs. Daily blood film examination showed persistent parasitaemia until the fourth day of oral treatment with quinine and tetracycline.

Case 6 was treated symptomatically for gastro-enteritis in Kenya four days before leaving. He felt unwell on the flight home but was not going to allow this to spoil his post-tour leave. Three days after returning to UK he was summoned to DKMH on 22nd April. No malaria parasites were ever demonstrated on twice daily and then subsequently daily films. A temperature spike of $40.5 \mathrm{C}$ (oral) and mild thrombocytopenia initiated empirical treatment with quinine and tetracycline. Immunofluorescent antibody titre proved to be positive suggesting a recent Plasmodium infection.

Case 7 was an experienced soldier with many prolonged, previous tropical tours but no past history of infection. He took his chemoprophylaxis assiduously, always slept under a mosquito net and used liberal amounts of repellant on his skin and clothing. He became unwell complaining of malaise and headache in Kenya two weeks before admission to DKMH. He had been bitten by an unidentified 'bug or beetle' in his sleeping bag and a local Kenyan doctor diagnosed "tick fever" and treated this with a five day course of tetracycline. He was brought back to the UK because of his illness but continued his chemoprophylaxis. His symptoms returned in the UK one week later and he consulted his GP with a history of cough, headache and night sweats. A blood film was taken and found to be negative for malarial parasites. Three days later on 6th May he presented to the A\&E Department at DKMH because of persistent malaise, fever and sweats and was found to have a $2 \% P$. falciparum parasitaemia.

\section{Discussion}

Breakthrough of falciparum malaria is due to a lack of effectiveness of the chemoprophylactic regime. The effectiveness is, in turn, determined by the compliance of the individual and the efficacy of the drugs. The efficacy is related to drug resistance and adequate blood levels.

When drug resistance, absorption and compliance are defective solely or in combination, chemoprophylaxis is weakened. Sole reliance on drugs is as naive as it is futile (4). Commonsense measures to minimise transmission are vital if infection is to be avoided (3). Clearly such sensible measures were lacking (Table 1) in all except Case 7.

Low blood levels of circulating chemoprophylactics occur if absorption is defective secondary to gastrointestinal upset. This may have played a role in Cases 1,4 and 6 , but it is more likely that their diarrhoea was a presenting symptom of malaria. Compliance is notoriously difficult to assess without biochemical testing and most patients over-estimate their consumption of tablets when in the field. Efforts to improve compliance reduce the incidence of breakthrough infection. Simpler dosing schedules of more effective drugs, such as mefloquine, are now indicated in areas of high chloroquine-resistant falciparum malaria despite greater problems with toxicity. $(1,5,6,7)$.

Simple preventive measures have been shown to make a remarkable difference. In some areas the use of mosquito nets alone reduces infection rates by $97 \%$ compared to no net at all (8). The impregnation of mosquito nets (9) and clothing with a permethrin-based repellant (Fig 1) is a readily available and effective method further to repel mosquitoes. Covering exposed flesh at dusk and using repellants regularly are timehonoured practices which are still appropriate.

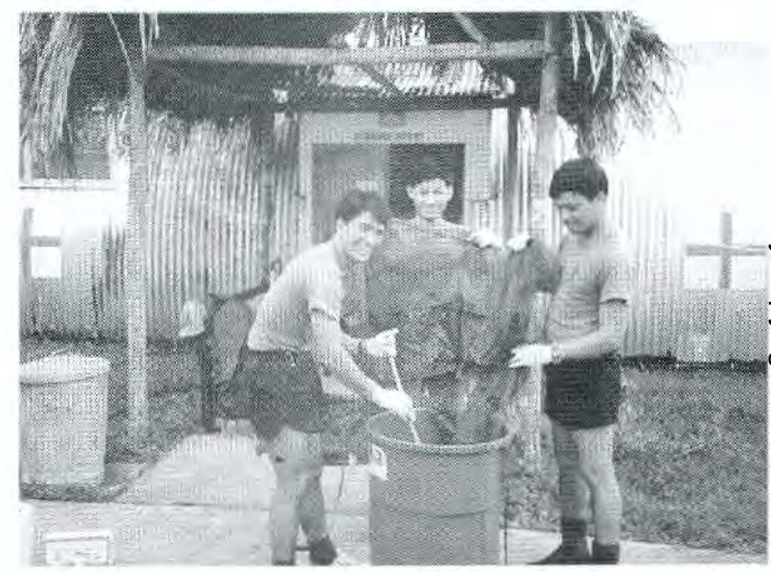

Fig 1. British Army Gurkhas dipping mosquito nets in diluted permethrin solution. October 91. Belize C.A.

It was interesting that Case 3 recrudesced after initial treatment with oral quinine only (Table 3 ). All other cases received quinine and tetracycline (Case 1 received doxycycline) to ensure complete cure. Case 3 was eventually treated with intravenous and then oral quinine followed by two doses of mefloquine base $500 \mathrm{mg}$. This clinical course suggests a degree of quinine resistance.

Delay in diagnosis is an important factor determining outcome. Case 7 suffered thirteen days before the diagnosis was made. He was partially treated with tetracycline in Kenya for another presumed illness. In this case, although chemoprophylaxis did not prevent symptomatic infection, it may have prevented severe disease (2). His GP sought only one negative film. Negative blood films do not exclude the diagnosis as Case 6 illustrated. Positive blood films are diagnostic in the 
non-immune traveller. Case 1 demonstrates how quickly fulminant falciparum infection can develop. He boarded the flight home feeling ill and collapsed during the journey.The RMO on board decided to continue to UK rather than detour to an unknown destination. This decision may have created a delay in initiating curative therapy. Falciparum malaria is a medical emergency requiring urgent intervention. This may have implications for airlines and those doctors who escort their charges from tropical zones.

Education of doctors and patients alike is essential. Case 6 had symptoms but did not seek medical help until he was instructed because he felt his holiday was more important despite a pre-tour lecture on such topics.

Screening an at risk but asymptomatic population for falciparum infection is controversial. However, the harvest of Cases 5 and 6 from screening 21 men was worthwhile as earlier treatment was possible. Screening consisted of a symptom enquiry, observation of temperature for a minimum of 24 hours and serial thick and thin blood films. Fellow travellers with similar exposure to an index case should be considered at high risk. The screening of such a group is justified by the benefit accruing from earlier diagnosis.

\section{Acknowledgement}

Our thanks to Dr A Tanner, Consultant Physician, and Dr C Rees, Senior House Officer, North Tees General Hospital and to Mrs Betty Ramsay for her secretarial services.

\section{REFERENCES}

1. BRADLEY D, et al. Prophylaxis against malaria fo travellers from the United Kingdom, Education and Debate, Br Med J 1993; 306: 1247-1252.

2. BRADley D, WARHURST D C. Communicable Disease्è Report, 1993, 3, Review 2, R25-R28.

3. Lewis S J, Davidson R N, Ross E J, Hall A P Severity of imported falciparum malaria: effect of taking antimalarial prophylaxis. $\mathrm{Br} \mathrm{Med} J$ 1992; 305: 등 741-743.

4. BIA F J. Malaria prophylaxis: taking aim at constantl moving targets. Yale J Biol Med 1992; 65(4): 329-36. ه

5. Lobel H O, Miani M, ENG T, BERnARD K W Hightower A W, Campbell C C. Long Term malariæ prophylaxis with weekly mefloquine. Lancet $1993 \overrightarrow{\overrightarrow{\vec{\omega}}}$ 341: 848-851.

6. Lobel H O, Bernard K W, Williams S, Hightowe A, Patchen L C, Campbell C C. Effectiveness and tolerance of long term malaria prophylaxis with mefloquine. Need for a better dosing regimen. JAMA 1991; 265(3): 361-4.

7. Centers for Disease Control. Recommendations fog the prevention of malaria among travellers. JAMA 1990; 263(20): 2729, 2734, 2737.

8. Nevill C G, Watkins W M, Carter J Y, Mung C G. Comparison of mosquito nets, progua hydrochloride, and placebo to prevent malaria. $\$ \overrightarrow{8}$ Med J 1988; 297: 401-3.

9. Sexton J D, Ruebush T K, Brandling Bennet A $\bar{\Phi}$ et al Permethrin impregnated curtains and bed n $8 \mathrm{t} s$ prevent malaria in Western Kenya. Trop Med Hyg. 1990; 43(1): 11-8. 